\title{
A INTEGRAÇÃO DOS PROGRAMAS DE ENSINO DAS DISCIPLINAS " ENFERMAGEM OBSTETRICA" E "ADMINISTRAÇÃO DE SERVIÇOS DE ENFERMAGEM EM MATERNIDADE"
}

\author{
Regina Toshie Takahashi* \\ Isilia Aparecida Sitva**
}

TAKAHASHI, R.T.; SILVA, I.A. A integraçăo dos programas de ensino das disciplinas "Enfermagem Obstétrica" e "Administraçăo de Serviços de Enfermagem em Maternidade". Rev. Esc. Enf. USP., v. 26, n. 3, p. - - dez., 1992.

Este relato descreve as dificuldades e os pontos positivos sentidos pelas alunas, enfermeiras e docentes que participaram no 29 semestre de 1989, da integraçao das disciplinas "Enfermagem Obstétrica " $e$ "Administraçao de Serviços de Enfermagem em Maternidade " na Escola de Enfermagem da Universidade de Sáo Paulo - EEUSP.

UNITERMOS: Ensino Integraçdo - disciplinas

\section{Introduçăo}

O programa de Habilitação em Enfermagem Obstétrica, com duração de 2 semestres, compreende o conteúdo das disciplinas "Enfermagem Obstétrica e Neonatal II" e "III" e "Administração de Serviços de Enfermagem em Maternidade".

Até o ano de 1988, o programa de Habilitação era realizado da seguinte forma: no 19 semestre os alunos cursavam a disciplina "Enfermagem Obstétrica II"; no 2o semestre, de agosto a outubro, "Enfermagem Obstétrica III"; e em novembro era desenvolvida "Administração de Serviços de Enfermagem em Maternidade".

Havia, no entanto, criticas por parte das alunas, de que esta separaçăo entre as disciplinas e o pouco tempo para as atividades de Administraçăo, dificultavam o aproveitamento, pois provocava uma ruptura entre os conteúdos relativos à assistência e à administraçăo; além disso, a falta de tempo nåo permitia a elas vivenciar e avaliar os resultados das propostas que faziam junto ao Serviço de Enfermagem do hospital.

- Enfermeira. Mestre em Enfermagem. Assistente do Departamento de Orientação Profissional da EEUSP, disciplina Administraçăo Aplicada à Enfermagem.

** Enfermeira. Mestre em Enfermagem. Assistente do Departamento de Enfermagem Materno-Infantil e Psiquiátrica da EEUSP, disciplina Enfermagem Obstétrica. 
A alternativa considerada viável para as modificações necessárias foi a de oferecer a disciplina de Administração em conjunto com a de Enfermagem Obstétrica III, no decorrer do $2 \%$ semestre do curso.

Depois de muita discussão com os elementos de ambas as disciplinas, colocamos em prática a proposta de integração, no $2^{\circ}$ semestre de 1989 , sendo utilizado o Hospital Universitário da USP como campo de estágio.

$O$ relato que segue pretende mostrar os resultados dessa integração, seus pontos positivos e negativos, as dificuldades e as alteraçס̃es planejadas para 1990.

\section{Sistemática de trabalho}

O ensino prático da disciplina "Enfermagem Obstétrica III" é realizado em diversas instituições hospitalares, o que acarreta o rodízio entre sub-grupos de alunas do referido programa. Dentre essas instituiçoes, o campo escolhido para realizarmos a integração projetada das disciplinas foi o Centro Obstétrico(CO), do Hospital Universitário(HU), por vário motivos: o HU é uma instituição na qual a EEUSP faz a integração docente assistencial. O CO é conhecido das alunas por já terem nele feito estágio no 10 semestre, portanto conhecem bem a planta física, as rotinas, os recursos humanos, os materiais disponíveis e as características da clientela assistida.

Esses conhecimentos anteriores facilitam o entrosamento das alunas com a equipe de enfermagem do $\mathrm{HU}$ e conseqüentemente facilitam a execução das atividades propostas.

A diretora da Divisão de Enfermagem do HU e a diretora do Centro Obstétrico do referido hospital aceitaram a metodologia por nos proposta que consistia em um trabalho integrado dos estágios das disciplinas de Enfermagem Obstétrica e Administração; a primeira visa assistir as parturientes de forma integral e a segunda,a a análise e o planejamento dos recursos necessários e disponiveis para que essa assistência de enfermagem seja a mais adequada.

A primeira etapa do ensino prático de Administração consistiu em um levantamento de dados dos recursos existentes em todas as áreas que compõem a Maternidade. Esse levantamento, feito por todas as alunas do grupo, possibilitou a descoberta dos pontos em que haviam deficiências e para os quais as alunas demonstravam interesse em atuar.

A segunda fase consistiu em um levantamento especifico na Unidade escolhida pelas alunas, concomitante à realização de um levantamento bibliográfico. A partir desses conteúdos foi iniciada uma série de discussões das quais participaram, além das alunas e docentes das disciplinas envolvidas, as enfermeiras do $\mathrm{CO}$ que tinham atuação direta no desenvolvimento das atividades das alunas.

Essas reuniões foram programadas para ocorrerem durante o estágio, na Unidade de $\mathrm{CO}$ com as alunas que lá estavam estagiando, havendo assim, uma continuidade no trabalho desenvolvido pelo grupo.

As alunas encarregavam-se da parte administrativa do $\mathrm{CO}$ ao mesmo tempo que atuavam junto as parturientes. Tal medida foi altamente positiva, pois elas haviam vivenciado a situação; qualquer proposta de modificação era primeiro experimentada por elas, e as sugestôes de modificação só eram implantadas após avaliação. 
No entanto, percebemos que o horário e a realização das reunióes dependia do movimento diário do $\mathrm{CO}$, bastante "flutuante", sendo que muitas foram remarcadas, algumas canceladas e de outras, a pauta não foi completada devido ao envolvimento das alunas na assistência às parturientes.

Outra dificuldade surgida foi o fato dos grupos de alunas estagiarem em locais distintos e terem apenas um contato semanal para a troca de idéias e discussర̃es, pois todas participaram da implantação das modificações sugeridas. Sentimos, também, a necessidade de discutir as idéias que vão surgindo com o desenvolvimento dos trabalhos. Para os próximos cursos idealizamos o planejamento de reuniōes semanais, agendadas nas quais o grupo todo deverá apresentar os relatórios dos sub-grupos, expondo a situação em que se encontram, a sistemática adotada e as propostas de modificação.

Recebemos ainda, das alunas, a sugestão de que cada grupo trabalhe um assunto, isto $E$, um aspecto da organização do Serviço de Enfermagem, desde o levantamento da situação até a implementação das soluções alternativas, pois a grande dificuldade relatada pelas alunas, é conciliar todo o grupo com visôes diferentes, sobre uma mesma proposta. Não há dúvida de que as discussões proporcionaram e contribuiram para o desenvolvimento pessoal de cada aluna, visto que nas discussões houve a possibilidade do aproveitamento de todas as situações.

$\mathrm{O}$ fato das alunas conhecerem e já estarem atuando no $\mathrm{CO}$, em contato com os funcionários, facilitou o processo de integração; estes sentiram a presença das alunas como fator positivo, relatando que a ajuda por elas proporcionada vêm de encontro ds suas necessidades de trabalho. Esse relacionamento possibilitou a realização do objetivo do estágio de Administração, que era o de vivenciar a organização de um Serviço de Enfermagem, que ressaltasse os aspectos de recursos humanos. A proposta de treinamento dos funcionários, em assuntos solicitados por eles, associada à situação das alunas, que estavam presentes em todos os momentos, permitiu o entrosamento entre a equipe de enfermagem do $\mathrm{CO}$ e o grupo de alunas, que foi considerado altamente benéfico para ambas as partes.

O grupo de alunas sugeriu que a disciplina de Administração fosse iniciada no começo do ano letivo, pois sentiu a necessidade de dispor de tempo maior para acompanhar todos os passos no processo junto ao funcionário.

Um outro ponto positivo foi o fato da diretora do Centro Obstétrico acompanhar e planejar em conjunto com os docentes a programação a ser executada. Além do grande interesse demonstrado pelas enfermeiras e das facilidades que as mesmas proporcionaram para a execução das atividades, elas contribuiram com importantes sugestões, que só enriqueceram a proposta de preparar melhor a equipe de enfermagem, para assistência mais adequada e de melhor padrão de qualidade.

\section{Considerações finais}

"É importante e proveitosa para todos a junção de esforços para o alcance de um objetivo."

Com essa afirmação podemos dizer que a integração das disciplinas "Enfermagem Obstétrica e Neonatal III" e "Administração da Assistência de Enfermagem em Maternidade" facilita o processo de ensino-aprendizagem da aluna, 
pois esta é preparada dentro de uma situação prática, onde vivencia a assistência de enfermagem, o que lhe possibilita organizar essa assistência dentro de situações reais.

Não há dúvida de que existem dificuldades e obstáculos, muitos sem solução imediata, porém, como uma primeira experiência, foi considerada válida para todos, enfermeiras, alunas e docentes.

Algumas modificações estão sendo planejadas, consideradas as avaliações do grupo para que a aluna do Curso de Habilitação em Enfermagem Obstétrica tenha melhor preparo para enfrentar a realidade que irá encontrar.

TAKAHASHI, R.T.; SILVA, I.A. The integrations between "Obstetrical Nursing" and "Maternity Nursing Service Administration". Rev. Esc. Enf. USP, v. 26, n. 3, p. - , dec., 1992.

This report describes the difficultes and the positive points perceived by the students, nurses and teachers that participated the integration between Obstetrical Nursing III and Maternity Nursing Service Administrations.

UNITERMS: Education, Integration 